\title{
Desempenho ponderal de cordeiros Santa Inês e F1 Dorper x Santa Inês em pastagens naturais ${ }^{1}$
}

\author{
Growth rate of Santa Inês and F1 Dorper Santa Inês in natural pasture
}

\author{
COSTA, Daniel dos Santos ${ }^{2}$; COSTA, Maria Dulcinéia da ${ }^{3 *}$; SILVA, Fredson \\ Vieira $^{3}$; ROCHA JÚNIOR, Vicente Ribeiro ${ }^{3}$; CARVALHO, Zaqueu Gonçalves ${ }^{4}$; \\ TOLENTINO, Daniella Cangussu ${ }^{4}$; LEITE, João Ricardo Avelar ${ }^{4}$
}

\author{
${ }^{1}$ Pesquisa parcialmente financiada pelo BNB. \\ ${ }^{2}$ Universidade Estadual de Montes Claros, Centro de Ciências Exatas, Departamento de Ciências \\ Agrárias, Janaúba, Minas Gerais, Brasil. \\ ${ }^{3}$ Universidade Estadual de Montes Claros, Centro de Ciências Exatas, Departamento de Ciências \\ Agrárias, Janaúba, Minas Gerais, Brasil. \\ *Endereço para correspondência: dulcineia.costa@unimontes.br
}

\section{RESUMO}

Objetivou-se com o trabalho avaliar o desempenho ponderal de dois genótipos de ovinos, Santa Inês e $\mathrm{F}_{1}$ Dorper x Santa Inês em pastagem de Panicum maximum cv. Massai. Foram utilizados oito fêmeas e oito machos, de cada genótipo, em delineamento inteiramente casualizado, em esquema fatorial $2 \times 2 \times 2$ (dois genótipos, dois sexos e duas idades de abate). Os dados foram submetidos à análise de variância com aplicação do teste de Scot-Knott com probabilidade de 5\%. Avaliaram-se peso ao nascimento, peso a desmama, peso final, ganho de peso médio diário e ganho de peso total. Houve efeito significativo do genótipo para peso ao nascimento e peso a desmama com os cordeiros Dorper x Santa Inês superiores. Para peso final não houve diferença significativa, pois o ganho de peso do desmame ao abate foi superior para o genótipo Santa Inês. Para ganho de peso total o efeito do genótipo foi importante visto que o $F_{1}$ Dorper x Santa Inês foi superior ao Santa Inês, enquanto o ganho de peso médio final foi igual para os dois genótipos avaliados. $\mathrm{O}$ efeito de sexo não foi significativo para nenhuma das características avaliadas. Não houve diferença entre peso final, ganho de peso médio diário e ganho de peso total nas diferentes idades de abate. A utilização da raça Dorper não refletiu maior retorno quando se mantém seus produtos em sistemas exclusivamente a pasto. Há necessidade de estudos bioeconômicos para verificar a aplicabilidade desta prática na região Norte de Minas Gerais.

Palavras-chave: cruzamento, ganho de peso, heterose, ovinos

\section{SUMMARY}

This work was carried out in order to evaluate the daily weight gain of two sheep genotypes, Santa Inês and $F_{1}$ Dorper $x$ Santa Inês. Eight females and eight males from each genotype, were used, in a entirely randomized design, in a factorial scheme $2 \times 2 \times 2$ (two genotypes, two sexes and two slaughter ages). Data were submitted to analysis of variance with application of the Scott-Knott test at 5\% probability. The birth weight, wean weight, final weight, average daily weight gain and total weight gain were evaluated. There was significant effect of genotype for birth weight and wean weight with superior Dorper x Santa Inês lambs. There was no significant difference for final weight, since weight gain from wean to slaughter was superior for Santa Inês genotype. For total weight gain, the effect of the genotype was important because $F_{1}$ Dorper $x$ Santa Inês was superior to, while daily weight gain was equal for the two evaluated genotypes. Sex effect was not significant for any evaluated characteristic. There was no difference between final weight, average daily weight gain and total weight gain for different slaughter ages. The use of Dorper breed did not reflect greater return when is intended to keep its products in systems exclusively for pasture. Bioeconomic studies are necessary for verifying applicability of that practice in the North of Minas Gerais.

Keywords: crossbreeding, heterosis, sheep, weight gain 


\section{INTRODUÇ̃̃̃O}

A ovinocultura no Norte de Minas Gerais encontra-se em expansão e representa uma importante atividade econômica, principalmente para os pequenos agricultores. O crescimento do rebanho em Minas Gerais teve início nos anos 2000, quando passou de 146.389 em 2001 para $242.801 \mathrm{em}$ 2007 (IBGE, 2009), o que corresponde a $32,72 \%$ do rebanho da região Sudeste (IBGE, 2009). Esta expansão acompanhou o cenário nacional e se deveu ao aumento de consumo de carne ovina que, em 2007 era de 120 mil toneladas, e estima-se que houve um leve incremento no consumo per capita que passou de $0,46 \mathrm{~kg}$ para $0,7 \mathrm{~kg}$ em 2008 (FAO, 2008).

O sistema de criação que prevalece na região Norte de Minas Gerais é o extensivo, no qual os animais são mantidos em piquetes com exploração máxima das forragens naturais e tem, como consequência, baixos rendimentos, o que ocorre em grande parte dos criatórios. Não apresentam padrão racial definido e predominam animais da raça Santa Inês e rebanhos com mais de 30 matrizes em reprodução. A grande maioria desses animais é abatida com idade avançada e acabamento insuficiente, o que resulta em carcaças fora do padrão almejado pelo mercado consumidor e gera dificuldades ao escoamento do produto. De acordo com Souza \& Leite (2000), isso se deve à falta de caracterização de um sistema de produção adequado, de maneira a usar raças apropriadas para cada objetivo de produção.

Em virtude do aumento do mercado consumidor têm-se observado maior interesse e investimento dos produtores na formação e manutenção das pastagens, e no melhoramento genético.
O uso de cruzamentos tem sido proposto como solução para compatibilizar produtividade com adaptabilidade nesses ambientes (EMBRAPA, 1993). FurushoGarcia et al. (2004) concluíram que o uso de raça especializada para carne no cruzamento com a raça Santa Inês melhorou significativamente $\mathrm{o}$ desempenho dos animais. A utilização de Dorper em sistemas de cruzamento industrial com Santa Inês promover melhor conformação na carcaça de cordeiros mestiços, quando abatidos na condição corporal gorda (SOUZA et al, 2008). Portanto, objetivou-se com o trabalho avaliar o desempenho ponderal de cordeiros Santa Inês e $F_{1}$ Dorper $\mathrm{x}$ Santa Inês submetidos a sistema exclusivo a pasto.

\section{MATERIAL E MÉTODOS}

O trabalho experimental foi conduzido no Capril Volta da Serra, no município de Januária, Norte de Minas Gerais. A topografia é plana com leves ondulações e altitude de $500 \mathrm{~m}$. O clima é tropical com transição para semiárido e a temperatura máxima atinge $42^{\circ} \mathrm{C}$, com mínima de $13,6^{\circ} \mathrm{C}$ e média anual de $29^{\circ} \mathrm{C}$. As chuvas são escassas e concentradas no verão, distribuídas de Novembro a Fevereiro com média pluviométrica anual de $750 \mathrm{~mm}$.

A pastagem era natural, com vegetação composta por espécies do cerrado e caatinga, em área de 4ha, com taxa de lotação de 8 animais/ha. Os animais foram mantidos em pastejo direto no período final das águas e início da seca e tiveram como fonte alimentar única o pastejo direto em Panicum maximum cv. Massai. Após as 16h30min os animais eram recolhidos no aprisco com bebedouros e cochos disponíveis para fornecimento de sal mineral. 
Rev. Bras. Saúde Prod. Anim., Salvador, v.13, n.1, p.237-243 jan/mar, 2012 http://www.rbspa.ufba.br ISSN 15199940

Foram utilizados 32 animais das raças Santa Inês e $F_{1}$ Dorper x Santa Inês, machos e fêmeas de mesma idade, do nascimento até o abate aos 120 e 150 dias.

Desde o nascimento os animais tiveram acesso ao pastejo direto, das $8 \mathrm{hs}$ às 16 h30min e eram pesados a cada 15 dias até ao abate, por meio de balança digital. Os cordeiros foram desmamados aos 90 dias e abatidos aos 120 e 150 dias de idade. Após o desmame os animais foram desverminados com Ivermectina a $1 \%$ na dosagem recomendada pelo fabricante e mantidos em pastejo direto das $8 \mathrm{hs}$ até as $16 \mathrm{~h} 30 \mathrm{~min}$, quando eram recolhidos ao aprisco e recebiam concentrado. O delineamento experimental foi inteiramente casualizado, em esquema fatorial $2 \times 2 \times 2$ sendo dois genótipos (Santa Inês e F1 Dorper x Santa Inês), dois sexos (machos e fêmeas) e duas idades de abate (120 e 150 dias).

Os dados foram submetidos à análise de variância, com a utilização da metodologia dos quadrados mínimos. Aplicou-se o teste de Scott Knott a 5\% de probabilidade. O modelo estatístico utilizado foi:

Yijkl $=\mu+\mathrm{G}_{\mathrm{i}}+\mathrm{S}_{\mathrm{j}}+\mathrm{A}_{\mathrm{k}}+\mathrm{GS}_{\mathrm{ij}}+\mathrm{GA}_{\mathrm{ik}}$

$+\mathrm{GSA}_{\mathrm{ijk}}+\mathrm{e}_{\mathrm{jikl}}$

sendo:

$\mathrm{Y}_{\mathrm{ijkl}}=$ uma das variáveis consideradas

$\mu=$ média geral da característica

$\mathrm{G}_{\mathrm{i}}=$ genótipo $(1,2)$

$\mathrm{Sij}=$ sexo i do iésimo genótipo (1 e 2)

Aijk = idade de abate $\mathrm{k}$ do sexo $\mathrm{j}$ do iésimo genótipo ( 1 e 2)

$\mathrm{GS}_{\mathrm{ij}}=$ interação genótipo x sexo

$\mathrm{GA}=$ interação genótipo $\mathrm{x}$ idade de abate

GSA = interação genótipo $\mathrm{x}$ sexo $\mathrm{x}$ idade de abate

eijkl = erro residual associado a cada observação.

\section{RESULTADOS E DISCUSSÃO}

As análises dos pesos ao nascer e dos pesos ao desmame são importantes para a seleção de ovinos, pois o desempenho dos borregos na fase pré-desmama indica a iniciação do seu potencial para o desempenho e a habilidade materna da ovelha mãe.

Não houve interação significativa $(\mathrm{P}>0,05)$ em todas as variáveis analisadas. $\mathrm{O}$ genótipo teve efeito significativo $(\mathrm{P}<0,05)$ sobre o peso ao nascimento $(\mathrm{PN})$ e o peso a desmama (PD), de acordo com a Tabela 1. Os animais F1 foram em média 11,0 e 20,0 $\%$ mais pesados ao nascimento e a desmama, respectivamente, do que os SI. Esta superioridade deveu-se ao efeito aditivo do cruzamento efetuado além da heterose ou vigor híbrido. Por outro lado, o sexo não teve efeito significativo sobre as variáveis $\mathrm{PN}$ e $\mathrm{PD}$, com médias de $4,04 \mathrm{~kg}, 4,03 \mathrm{~kg}$; $19,29 \mathrm{~kg}, 18,36 \mathrm{~kg}$ para fêmeas e machos respectivamente (Tabela 1). Porém, Quesada et al. (2002), afirmaram que o sexo afetou $(\mathrm{P}<0,05)$ o peso ao nascer e aos 120 dias dos cordeiros da raça Santa Inês.

Tabela 1. Médias do peso ao nascimento (PN) e peso a desmama (PD) e número de animais $(\mathrm{N})$ de acordo com o grupo genético e sexo

\begin{tabular}{lccc}
\hline \multicolumn{1}{c}{ Item } & $\mathrm{N}$ & $\mathrm{PN}^{1}$ & $\mathrm{PD}$ \\
\hline Genótipo $^{1}$ & & & \\
\hline SI & 16 & $3,82^{\mathrm{B}}$ & $17,09^{\mathrm{B}}$ \\
D x SI & 16 & $4,25^{\mathrm{A}}$ & $20,57^{\mathrm{A}}$ \\
\hline Sexo & & & \\
\hline Fêmea & 16 & $4,04^{\mathrm{A}}$ & $19,29^{\mathrm{A}}$ \\
Macho & 16 & $4,03^{\mathrm{A}}$ & $18,36^{\mathrm{A}}$ \\
\hline
\end{tabular}

Letras diferentes na coluna indica diferença significativa ao nível de 5\% pelo teste de Scott - Knott.

${ }^{1} \mathrm{D}=$ Dorper; $\mathrm{SxD}=\mathrm{F}_{1}$ Dorper $\mathrm{X}$ Santa Inês. 
Estes resultados estão de acordo com trabalho de Chagas et al. (2007) que verificaram em grupos genéticos distintos, Santa Inês e Dorper x Santa Inês em diferentes ecossistemas brasileiros, diferença significativa $(\mathrm{P}<0,05)$ para peso ao nascer, com média de $3,63 \mathrm{~kg}$ e $4,24 \mathrm{~kg}$, respectivamente. Já Machado et al. (1999) encontraram em animais mestiços Santa Inês e Santa Inês x Texel, em confinamento, pesos médios de $3,22 \mathrm{~kg}$ e $3,82 \mathrm{~kg}$, respectivamente. Por outro lado Rocha et al. (2004) testaram o desempenho de cordeiros cruzados e encontraram valores inferiores para os cordeiros SI (3,04Kg), D x SI (3,36kg).

$\mathrm{O}$ peso médio ao desmame encontrado neste experimento está de acordo com os encontrados por Chagas et al. (2007), cuja média foi $18,6 \mathrm{Kg}$ para os mestiços Dorper Santa Inês e 17,6 para os Santa Inês, desmamados aos 90 dias. Os animais $F_{1}$ tiveram por volta de $3,5 \mathrm{~kg}$ a mais que os animais Santa Inês, o ganho de peso real foi de $15,25 \mathrm{~kg}$ e $13,27 \mathrm{~kg}$, respectivamente. Como a base genética materna foi a mesma, o maior peso ao desmame dos cordeiros mestiços Dorper $x$ Santa Inês em relação aos animais Santa Inês deveu-se provavelmente à superioridade da raça Dorper, especializada para corte somados à heterose. Segundo Barbosa Neto et al. (2010), o peso ao desmame e o ganho de peso do nascimento ao desmame são fortemente influenciados por efeitos genéticos não aditivos como a heterose individual e materna, além da recombinação. Contudo, há que se considerar a habilidade materna da raça Santa Inês uma vez que o efeito materno exerce grande influência nas características de crescimento, particularmente até a desmama (SOUSA et al., 2006). De acordo com Motta et al. (2000), o efeito materno influi diretamente no peso a desmama e a produção leiteira é o fator determinante. Ainda assim, Tonetto et al (2004) relataram que à medida que os cordeiros aumentam a idade, o ganho médio diário diminui devido à dependência dos cordeiros pelo leite materno nas primeiras semanas de lactação.

No período pós-desmama, no qual não há influência da mãe, o genótipo não teve efeito no peso final dos cordeiros, com $19,35 \mathrm{~kg}$ e $20,75 \mathrm{~kg}$ para os animais Santa Inês e Dorper Santa Inês respectivamente. $\mathrm{O}$ ganho real do peso do desmame ao peso final foi da ordem de 2,16kg para o genótipo Santa Inês e $0,18 \mathrm{~kg}$ para Dorper Santa Inês. Esta diferença pode ser explicada pela adaptação e rusticidade da raça Santa Inês às condições climáticas adversas da região em relação aos mestiços Dorper Santa Inês, quando estes animais foram criados exclusivamente a pasto.

$\mathrm{O}$ peso final (PF), ganho de peso total (GPT) e ganho de peso médio diário (GPMD) foram similares para as idades de abate aos 120 e 150 dias e sexo, conforme a Tabela 2.

Carneiro et al. (2007) avaliaram ovinos aos 30, 60, 90, 120 e 150 dias, idades similares às encontradas neste trabalho, apesar de submetidos a sistema semiintensivo e da inclusão de suplementação de mistura múltipla comercial, relataram pesos finais de $22,04 \mathrm{~kg}$ e $26,51 \mathrm{~kg}$ para animais F1 Dorper x Santa Inês aos 120 e 150 dias respectivamente, resultados superiores aos do presente estudo.

$\mathrm{O}$ efeito do genótipo influenciou significativamente $(\mathrm{P}<0,05)$ o ganho de peso total, o genótipo Dorper x Santa Inês foi superior ao Santa Inês em $2,73 \mathrm{~kg}$ com médias de $17,38 \mathrm{~kg}$ e $14,65 \mathrm{~kg}$ respectivamente. Valores de ganho de peso total de $13,8 \mathrm{~kg} ; 14,8 \mathrm{~kg} ; 15,9 ; 16,2 \mathrm{~kg}$ foram encontrados por Murta et al. (2009) em ovinos do genótipo Santa Inês ao incluir $0,0 \% ; 0,75 ; 1,50 \%$ e $2,25 \%$ de oxido de cálcio no bagaço de cana. 
Rev. Bras. Saúde Prod. Anim., Salvador, v.13, n.1, p.237-243 jan/mar, 2012 http://www.rbspa.ufba.br ISSN 15199940

Tabela 2. Médias de peso final (PF), ganho de peso total (GPT) e ganho de peso médio diário (GPMD) de cordeiros de acordo com a idade de abate, o genótipo e o sexo

\begin{tabular}{lcccc}
\hline Item & $\mathrm{N}^{1}$ & $\mathrm{PF}^{2}$ & GPT $(\mathrm{kg})$ & GPMD $(\mathrm{g})$ \\
\hline Idade de abate & & & & \\
\hline 120 & 16 & $19,35^{\mathrm{A}}$ & $15,36^{\mathrm{A}}$ & $130^{\mathrm{A}}$ \\
150 & 16 & $20,75^{\mathrm{A}}$ & $16,63^{\mathrm{A}}$ & $120^{\mathrm{A}}$ \\
\hline Genótipo $^{3}:$ & & & & \\
\hline SI & 16 & $19,26^{\mathrm{A}}$ & $14,65^{\mathrm{B}}$ & $120^{\mathrm{A}}$ \\
D x SI & 16 & $20,83^{\mathrm{A}}$ & $17,38^{\mathrm{A}}$ & $130^{\mathrm{A}}$ \\
\hline Sexo: & & & & \\
\hline Fêmea & 16 & $20,49^{\mathrm{A}}$ & $16,46^{\mathrm{A}}$ & $130^{\mathrm{A}}$ \\
Macho & 16 & $19,61^{\mathrm{A}}$ & $15,56^{\mathrm{A}}$ & $120^{\mathrm{A}}$ \\
\hline
\end{tabular}

${ }^{\mathrm{T}}$ Número de animais; ${ }^{2}$ Letras diferentes na mesma coluna indicam diferença significativa ao nível de $5 \%$ pelo teste de Scott - Knott. ${ }^{3}$ SI= Santa Inês; D x SI= F1 Doper x Santa Inês.

Animais mestiços Santa Inês quanto são submetidos a confinamento conseguem ganho de peso médio diário superiores a 130g (FERNANDES et al., 2007; FREITAS et al., 2005). Os resultados evidenciados no presente experimento para ganho de peso médio diário, apesar de não expressarem significância ao avaliar os genótipos, foram superiores aos encontrados por Pires et al. (2004), que observaram ganho de peso médio diário de 90,45 e 82,99g respectivamente, em ovinos 5/8 Santa Inês.

Um dos principais fatores que contribui para elevar o ganho de peso médio diário dos cordeiros é a inclusão de concentrado na dieta. De acordo com Neres et al. (2001), em pastagens nativas, a obtenção de boa produtividade e qualidade de carne ovina torna-se difícil devido à carência de nutrientes, o que justifica a necessidade de utilização de pastagens cultivadas, suplementação em pastejo e/ou confinamento para expressão máxima do potencial genético dos animais. Souza \& Leite (2000) observaram ganho de peso médio diário de 288,2g em cordeiros do genótipo Dorper, em pastejo, que recebiam suplementação. Assim, faz-se necessária a suplementação para se obter melhores resultados quando se utiliza cruzamentos a fim de propiciar o melhor retorno.

O sexo não teve efeito significativo para os parâmetros avaliados. Barros et al. (2004) também não evidenciaram efeito significativo do sexo $(\mathrm{P}>0,05)$ para o ganho de peso médio diário.

Em sistema exclusivo a pasto na época de maior disponibilidade de forragem na região do Norte de Minas, os cordeiros mestiços Dorper x Santa Inês tiveram peso ao nascer, peso a desmama, ganho de peso durante este período e ganho de peso total superior aos cordeiros Santa Inês. Assim, o ganho de peso do período de desmame (90 dias), ao abate (120 e 150 dias) foi superior para os animais Santa Inês, o ganho de peso médio diário e o peso final foram semelhantes, enquanto $o$ sexo e a idade de abate não tiveram efeito significativo sobre as características citadas. É importante salientar que em sistemas de produção nos quais se utiliza cruzamento como ferramenta para se obter melhoramento, faz-se necessário melhorar as condições 
Rev. Bras. Saúde Prod. Anim., Salvador, v.13, n.1, p.237-243 jan/mar, 2012 http://www.rbspa.ufba.br ISSN 15199940

nutricionais e sanitárias para que todo o potencial genético seja expresso.

A implantação da raça Dorper como melhoradora deve ser avaliada de forma criteriosa quando se pretende manter seus produtos em sistemas exclusivamente a pasto.

Mais estudos são necessários com estes genótipos em pastagens para avaliar o retorno bioeconômico.

\section{AGRADECIMENTOS}

Ao Banco do Nordeste do Brasil, FAPEMIG e CAPES pelo apoio financeiro e ao Capril da Serra pela realização do experimento.

\section{REFERÊNCIA}

BARBOSA NETO, A.C.; OLIVEIRA, S.M.P.; FACÓ, O.; LOBO, R.N.B. Efeitos genéticos aditivos e não-aditivos em características de crescimento, reprodutivas e habilidade materna em ovinos das raças Santa Inês, Somalis Brasileira, Dorper e Poll Dorset.

Revista Brasileira de Zootecnia, v.39, n.9, p.1943-1951, 2010.

BARROS, N.N.; VASCONCELOS, V.R.; LOBO, R.N.B. Características de crescimento de cordeiros de cordeiros F1 para abate no semi-árido do Nordeste do Brasil. Pesquisa Agropecuária

Brasileira, v.39, p.809-814, 2004.

CARNEIRO, P.L.; MALHADO, C.H.M.; SOUZA JÚNIOR, A.A.O.; SILVA, A.G.S.; SANTOS, F.N.; SANTOS, P.F; PAIVA, S.R. Desempenho ponderal e diversidade fenotípica entre cruzamentos de ovinos Dorper com raças locais.

Pesquisa Agropecuária Brasileira, v.42, n.7, p.991-998, 2007.
CHAGAS, A.C.S.; OLIVEIRA, M.C.S.; FERNANDES, L.B.; MACHADO, R.; ESTEVES, S.N.; SALES, R.L. BARIONI JÚNIOR, W. Ovinocultura: controle de verminose, mineralização, reprodução e cruzamentos na Embrapa Pecuária Sudeste. São Carlos: Embrapa Pecuária Sudeste, 2007. 44p. (Documentos, 65).

EMPRESA BRASILEIRA DE PESQUISA AGROPECUÁRIA EMBRAPA. Avaliação econômica e produtiva de dois sistemas de produção de ovinos de corte utilizando cruzamentos, em Sobral (CE). Sobral: EMBRAPA-CNPC, 1993. 35p.

FOOD AND AGRICULTURE ORGANIZATION OF THE UNITED NATIONS - FAO. Food outlook, n.2, Rome: GIEWS-FAO, 2007. 91p.

FERNANDES, M.A.M; MONTEIRO, A.L.G.; BARROS, C.S.; GAZDA, T.L., PIAZETTA, R.G. DITTRICH, J.R. ; GASPERINI, C. Desempenho de cordeiros puros e cruzados Suffolk e Santa Inês. Revista da FZVA- Uruguaiana, v.14, n.2, p.207-216, 2007.

FREITAS, D.C.; OLIVEIRA, G.J.C.; JAEGER, S.M.P.; CAVALCANTI, A.S.R.; LEDO, C.A.S. TORRES, P.E.L.M.V.T; FILHO, A.O.L.; SANTANA, P.F.A.; ALMEIDA, D.C. Idade de desmama de cordeiros deslanados para terminação em confinamento, no litoral norte da Bahia. Revista Brasileira de Zootecnia, v.34, n.4, p.1392-1399, 2005.

FURUSHO-GARCIA, I.F.; PEREZ, J.R.O.; BONABURIO, S.; ASSIS, R.M; PEDREIRAS, B.C; SOUZA, X.R. Desempenho de cordeiros Santa Inês puros e cruzas Santa Inês com Texel, Ilhe de France e Berganácia. Revista

Brasileira de Zootecnia, v.33, n.6, p1591-1603, 2004. 
Rev. Bras. Saúde Prod. Anim., Salvador, v.13, n.1, p.237-243 jan/mar, 2012 http://www.rbspa.ufba.br ISSN 15199940

INSTITUTO BRASILEIRO DE GEOGRAFIA E ESTATÍSTICA IBGE. Pesquisa Pecuária Municipal. 2009. Disponível em:

$<$ www.ibge.com.br>. Acesso em: 20 jan. 2010.

MACHADO, R.; SIMPLICIO, A. A.; BARBIERI, M. E. Acasalamento entre ovelhas deslanadas e reprodutores especializados para corte: desempenho produtivo até a desmama. Revista Brasileira de Zootecnia, v.28, n.4, p.706-712, 1999.

MOTTA, O.S.; PIRES, C.C.; SILVA, J.H.; ROSA, G.T.; FULBER, M.; GARCIA, A.G. Produção de leite de ovelhas e suas correlações com o ganho de peso dos cordeiros. Revista Brasileira de Zootecnia, v.29, n.1, p.273-279, 2000.

MURTA, R.M.; CHAVES, M.A.; SILVA, F.V.; BUTERI, C.B.; FERNANDES, O.W.B.; SANTOS, L.X. Ganho em peso e características de carcaça de ovinos confinados alimentados com bagaço de cana hidrolisado com óxido de cálcio. Ciência Animal Brasileira, v.10, n.2, p.438-445, 2009.

NERES, M.A.; MONTEIRO, A.L.G.; GARCIA, C.A.; COSTA, C.; ARRIGONI, M.B.; ROSA, G.J.M. Forma física da ração e pesos de abate nas características de carcaça de cordeiros em creep feeding . Revista Brasileira de Zootecnia, v.30, n.3, p.948-954, 2001. Supl. 1.

PIRES, A.J.V.; CARVALHO JÚNIOR, J.N.; SILVA, F.F.; VELOSO, C.M.; SOUSA, A.L.; OLIVEIRA, T.N.; SANTOS, C.L.; CARVALHO, G.G.P.; BERNARDINO, F.S. Farelo de cacau na alimentação de ovinos. Revista Ceres, v.51, n.293, p.33-43, 2004.
QUESADA, M.; MCMANUS, C.; COUTO, F. A. A. Efeitos genéticos e fenotípicos sobre características de produção e reprodução de ovinos deslanados no Distrito Federal. Revista Brasileira de Zootecnia, v.31, n.1, p.342-349, 2002. Supl.

ROCHA, M.H.M; SUSIN, I.; PIRES, A.V.; FERNANDES JR, J.S.; MENDES, C.Q.; Performance of Santa Ines lambs fed diets of variables crude protein level. Scientia Agricola, v.61, n.2, p.141-145, 2004.

SOUSA, J.E.R.; OLIVEIRA, S.M.P.; LIMA, F.A.M.; SILVA, F.L.R.; SILVA, M.A. Efeitos genéticos e de ambiente para características de crescimento em ovinos Santa Inês no Estado do Ceará.

Revista Ciência Agronômica, v.37, n.3, p.364-368, 2006.

SOUZA, W.H.; CARTAXO, F.Q.; CEZAR, M.F.; GONZAGA NETO, S.; CUNHA, M.G.G.; SANTOS, N.M. Desempenho e características de carcaça de cordeiros terminados em confinamento com diferentes condições corporais.

Revista Brasileira Saúde Produção Animal, v.9, n.4, p. 795-803, 2008.

SOUZA, W.H.; LEITE, P.R.M. Ovinos de corte. A raça Dorper. João Pessoa: EMEPA, 2000. 76 p.

TONETTO, C.J.; PIRES, C.C.; MULLER, L.; ROCHA, M.G.; SILVA, J.H.S.; CARDOSO, A.R.; NETO, D.P. Ganho de peso e características da carcaça de cordeiros terminados em pastagem natural suplementada, pastagem cultivada de Azevém (Lolium multiflorum Lam.) e confinamento. Revista

Brasileira Zootecnia, v.33, n.1, p.225233, 2004.

Data de recebimento: 09/05/2011

Data de aprovação: 09/02/2012 